\title{
Perilaku Konsumsi Rumah Tangga Dan Pengaruhnya Terhadap Kebijakan Makro Ekonomi Kabupaten Bangkalan
}

\section{Henny Oktavianti ${ }^{1{ }^{1 *}}$, Zakik $^{2}$}

1,2 Program Studi Ekonomi Pembangunan, Universitas Trunojoyo Madura

\section{Informasi Artikel \\ Sejarah artikel: \\ Diterima Maret 2017 \\ Disetujui Maret 2017 \\ Dipublikasikan Maret 2017}

\section{Keywords: \\ Consumption, \\ Household,}

Macro Economics,

\begin{abstract}
A B S T R ACT
The aims of this paper to formulate a model of moslem household consumption. By focusing on moslem household is considered important because the majority of Indonesia's population is Muslim. To support the researchers took the study site on the Madura, because this region reflects the domestic life of moslem, where the life is very religious. Consumption modelling is considered important because the trend of people / households in the decision to consume will affect great on the economy. Factors outside the economy, such as lifestyle and environment often influence the decision of the public to consume. therefore this research is needed to find the right policy face a society that such behavior. Output this study is a model of household consumption and macro-economic policy areas. Therefore, the methodology used is quantitative with the use of regression as a statistical tool and using explanatory techniques (explanatory research).
\end{abstract}




\section{Pendahuluan}

Konsumsi rumah tangga merupakan salah satu kegiatan ekonomi rumah tangga untuk memenuhi berbagai kebutuhan barang dan jasa. Dari komoditi yang dikonsumsi itulah keluarga akan mempunyai kepuasan tersendiri. Oleh karena itu, konsumsi seringkali dijadikan salah satu indikator kesejahteraan keluarga. Makin besar pengeluaran untuk konsumsi barang dan jasa, maka makin tinggi tahap kesejahteraan keluarga tersebut (Akmal, 2003).

Mengingat konsumsi memiliki peranan sentral, mengetahui perilaku konsumsi, merupakan kebutuhan yang mendesak untuk bisa memahami jalannya perekonomian dari waktu ke waktu. Lebih dari itu rumusan kebijakan ekonomi makro harus selalu didasarkan pada pemahaman yang benar mengenai perilaku konsumsi, karena salah satu dampak akhir dari sebuah kebijakan makro ekonomi sangat ditentukan oleh besarnya angka pengganda, dan besarnya angka tersebut sangat tergantung dari perilaku konsumsi yang tercermin pada besarnya hasrat konsumsi marjinal. Namun sayangnya, studi mengenai konsumsi masih sangat terbatas untuk kasus Indonesia. Padahal teori dan hasil-hasil penelitian di negara lain telah mengalami perkembangan yang sangat cepat.

Banyaknya penelitian yang nenunjukkan tentang rendahnya nilai rasionalitas dalam berkonsumsi, mendorong peneliti untuk lebih banyak mengetahui faktorfaktor yang sangat berpengaruh terhadap pola konsumsi pada masyarakat Kabupaten Bangkalan Madura. Yang selanjutnya diharapkan akan dapat menghasilkan model pola konsumsi serta perumusan kebijakan stabilitator perekonomian.

Penelitian ini mempunyai tujuan khusus untuk merumuskan model konsumsi rumah tangga. Pemodelan dibuat untuk membantu pemilihan dan atau pembuatan kebijakan makro ekonomi daerah yang tepat. Sehingga stabilisasi ekonomi dapat tercipta. Adapun tujuan khusus dalam penelitian ini, dapat dijabarkan ke dalam point-point di bawah ini: (a) Perumusan model pola konsumsi; (b) Analisis faktor pendorong konsumsi rumah tangga; (c) Kesesuaian/penyimpangan dengan teori ekonomi yang ada; (d) Demilihan kebijakan makro ekonomi daerah yang ada.

\section{Pengertian konsumsi}

Dalam kehidupan sehari-hari konsumsi hanya dimaksudkan sebagai hal yang berkaitan dengan makanan dan minuman. Sehingga semua barang dan jasa yang dimanfaatkan oleh konsumen untuk memenuhi kebutuhannya disebut pengeluaran konsumsi. Menurut Bannoch dalam bukunya "economics" menjelaskan bahwa konsumsi merupakan pengeluaran total untuk memperoleh barang dan jasa dalam suatu kegiatan perekonomian dalam jangka waktu tertentu (dalam satu tahun) pengeluaran. Pengeluaran konsumsi rumah tangga tidak terbatas hanya pengeluaran untuk barang-barang yang tidak tahan lama, tetapi dapat diketahui meliputi pengeluaran untuk barang-barang tahan lama (Waluyo, 2007).

\section{Teori Konsumsi Ernst Engel}

Teori konsumsi menurut Engel menyatakan bahwa saat pendapatan meningkat, proporsi pendapatan yang dihabiskan untuk membeli makanan berkurang, bahkan jika pengeluaran aktual untuk makanan meningkat. Hal ini berarti hukum Engel menyatakan bahwa tingkat kesejahteraan dikatakan membaik bila perbandingan pengeluaran untuk konsumsi makanan cenderung sedikit dan sebaliknya pengeluaran untuk non-makanan cenderung tinggi. Adanya pergeseran permintaan konsumsi tersebut dikarenakan beberapa faktor seperti, (a) tingkat pendapatan per kapita (per capita income) masyarakat; (b) cita rasa atau selera (taste) konsumen terhadap barang itu; (c) harga barang lain (prices of related goods), teru- 
tama barang pelengkap (complementary goods) dan barang pengganti (substitution goods); (d) harapan atau perkiraan konsumen (consumer expectation) terhadap harga barang yang bersangkutan.

Klasifikasi untuk permintaan barang konsumsi terdiri dari Superior good (barang mewah), Inferior good (barang bermutu rendah) dan Normal good (barang normal). Superior good adalah barang yang perubahan jumlah barang yang diminta lebih besar dari pada perubahan pendapatan konsumen. Inferior good adalah barang yang apabila pendapatan konsumen bertambah maka jumlah barang yang diminta justru semakin berkurang atau barang yang sudah tidak menjadi mode lagi di kalangan anggota masyarakat seperti jenis makanan tradisional semacam jagung bakar, gethuk bahkan bukan hanya makanan saja juga seperti alat transportasi misalnya sepeda.

MenurutNicholson(1997)menjelaskan bahwa kurva engel merupakan suatu fungsi dimana untuk menghubungkan keseimbangan jumlah komoditi yang dibeli konsumen pada berbagai tingkat pendapatan. Kurva engel juga menjadi salah satu konsep yang sangat penting dalam membahas kesejahteraan ekonomi (economic walfare) dengan menganalisis pola pengeluaran rumah tangga. Besar kecilnya suatu pendapatan dan pengaruhnya terhadap barang dan jasa yang dikeluarga dinyatakan dalan kurva engel sebagai berikut :
Gambar 1 menunjukkan kurva engel yang menggambarkan dua bentuk kurva engel. Dalam gambar 1.a menunjukkan kurva engel mempunyai kemiringan dari bawah ke atas sedikit datar. Artinya bahwa perubahan pendapatan tidak mengakibatkan perubahan yang berarti terhadap perubahan konsumsi. Kurva engel yang menunjukkan bahwa barang tetap dibeli meskipun pendapatan konsumsi rendah, tetapi jumlah tersebut tidak akan bertambah secara cepat dengan adanya kenaikan pendapatan. Gambar 1.b menunjukkan bentuk kemiringan dari kiri bawah ke kanan atas tapi relatif lebih tegak. Kurva ini mengandung arti bahwa adanya perubahan pendapatan konsumen akan diikuti dengan perubahan jumlah barang dibeli.

\section{Teori Konsumsi dengan Hipotesis Pendapatan Relatif (Relative Income Hypotesis)}

Menurut Duesenberry dalam teori hipotesis pendapatan relatifnya (relative income hypotesis) menyatakan bahwa selalu ada kecenderungan setiap anggota masyarakat untuk meningkatkan konsumsi mereka begitu terjadi peningkatan pendapatannya. Fluktuasi tingkat pendapatan menyebabkan perilaku konsumen (rumah tangga) akan berbeda dalam jangka pendek dan panjang.

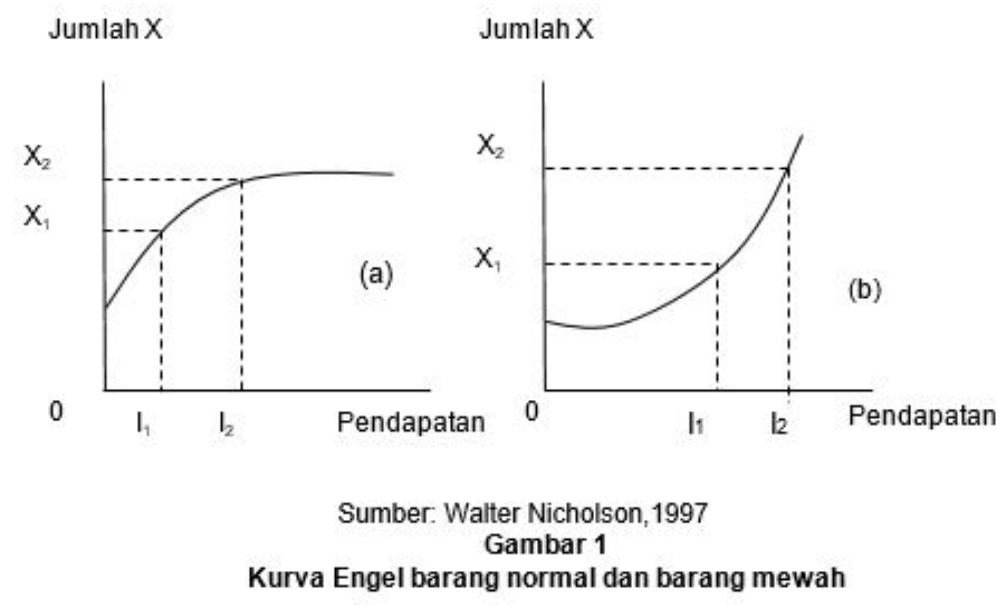


Teori Konsumsi dengan Hipotesis Pendapatan Permanen (Permanent Income Hypotesis)

Dalam buku yang diterbitkan pada tahun 1957, Milton Friedman menawarkan hipotesis pendapatan-permanen (permanent income hypotesis) untuk menjelaskan perilaku konsumen. Hipotesis pendapatan-permanen Friedman melengkapi hipotesis daur hidup Modigliani: keduanya menggunakan teori konsumsi Irving Fisher untuk menyatakan bahwa konsumsi seharusnya tidak hanya bergantung pada pendapatan sekarang. Pada hipotesis pendapatan-permanen menekankan bahwa manusia mengalami perubahan acak dan temporer dalam pendapatan mereka dari tahun ke tahun (Mankiw, 2003). Jika hipotesis pendapatan permanen benar dan konsumen memiliki ekspektasi rasional maka perubahan konsumsi mungkin akan tak terduga dan perubahan ini dikenal sebagai random walk. Alasan yang diberikan sebagai berikut: jika hipotesa ini benar maka fluktuasi pendapatan akan diikuti oleh konsumen dengan mencoba untuk mengurangi fluktuasi konsumsinya. Tetapi dengan adanya ekspektasi terhadap tingkat pendapatan akan mengubah tingkat konsumsi.

Hipotesis Robert Hall dan Random Walk Hipotesis pendapatan-permanen didasarkan pada model pilihan antarwaktu Fisher (Fisher's model of intertemporal choice). Hipotesis itu membangun gagasan bahwa konsumen yang berpandangan ke depan mendasarkan keputusan konsumsinya tidak hanya pada pendapatan sekarang, tetapi juga pada pendapatan yang mereka harapkan di masa depan. Jadi, hipotesis pendapatan-permanen menyatakan bahwa konsumsi bergantung pada ekspektasi seseorang.

\section{Pola Konsumsi Rumah Tangga}

Pola konsumsi seseorang atau suatu keluarga ditentukan oleh faktor ke- butuhan manusia yang merupakan pengeluaran untuk konsumsi dan alat untuk memenuhi kebutuhan yang merupakan penghasilan. Seseorang disebut konsumen karena ia menggunakan barang. Filsafat dasar manusia mengkonsumsi (menggunakan) barang-barang kebutuhan nya tadi disebut Pola Konsumsi. Oleh karena manusia dalam hidup bermasyarakat berhimpun dalam keluarga maka pola konsumsi ini merupakan pola konsumsi keluarga. Ini berarti setiap keluarga bahkan setiap negara dapat menentukan pola konsumsinya sendiri berdasar pandangan dan falsafah hidupnya.

Penentuan pola konsumsi ini merupakan keputusan yang dapat diambil dari seseorang atau sekelompok orang sesuai dengan pandangan hidupnya. Pengambilan keputusan ini mendaratkan banyak pengaruh. Pengaruh ini dapat berupa faktor intern (perilaku, sikap hidup, motivasi), dan faktor-faktor exstern (budaya, lingkungan, iklan, peraturan). Manusia mempunyai kebutuhan tersebut (penghasilan) terbatas. Disini seseorang dihadapkan pada perbuatan memilih. Untuk melaksanakan perbuatan memilih ini seseorang dipengaruhi oleh pribadi dan lingkungan hidupnya (Prasetyo, 2003).

Pada hakekatnya seseorang mengkonsumi barang karena kebutuhan untuk hidup. Oleh karena keputusan manusia yang tidak terbatas tadi maka lingkungan hidupnya sangat mudah menjadi faktor yang mempengaruhi keputusan memilihnya. Barang bagi seseorang bukan lagi sekedar untuk memenuhi kebutuhan untuk hidup tetapi juga untuk kenikmatan dan gengsi. Kenikmatan dan gengsi adalah emosi yang mendorong seseorang untuk terus berusaha memenuhi kebutuhannya. Walaupun sudah terpenuhi kebutuhan pokoknya. Situasi semacam ini "memupuk" manusia menjadi serakah.

Dengan kemajuan dalam tingkat penghasilan, pola konsumsi juga berubah. Hal ini dapat dilihat dengan jelas, apa- 
bila pengeluaran-pengeluaran sejumlah keluarga kita golong-golongkan menjadi beberapa kelompok, kemudian kita perbandingkan pengeluaran keluarga yang tergolong cukup kaya.

Maka terlihat bahwa terjadi suatu pergeseran dalam pengeluaran untuk konsumsi. Dalam keluarga yang miskin, hampir seluruh penghasilan akan habis untuk kebutuhan primer, makan dan minum. Jika tingkat penghasilan suatu keluarga naik (orang menjadi lebih kaya), maka jumlah pengeluaran uang untuk kebutuhan primer (khususnya makanan) juga akan bertambah banyak. Tetapi jika diperhatikan berapa persentase dari penghasilan dikeluarkan untuk berbagai kebutuhan, ternyata bahwa persentase penghasilan yang dibelanjakan untuk makanan akan berkurang, dari $80 \%$ menjadi $70 \%, 60$ atau 50\%. Sebaliknya persentase atau bagian penghasilan yang dibelanjakan untuk kebutuhan-kebutuhan lain (perumahan, pendidikan, kesehatan, rekreasi, dll) itu bertambah besar, dari $20 \%$ menjadi $30 \%$ sampai $40 \%$. Gejala ini dalam ilmu ekonomi dikenal dengan nama Hukum Engel (Gilarso, 1986).

\section{Metodologi penelitian Metode Analisa}

Penelitian ini merupakan kombinasi dari penelitian kuantitatif dan penelitian ekplanatori (explanatory research). Penelitian yang bersifat kuantitatif adalah penelitian yang menyangkut pengujian hipotesis atau hubungan antar variabel penelitian yang telah melalui proses pengolahan data-data kuantitatif. Penelitian eksplanatori penelitian yang bersifat menerangkan adalah penelitian yang menyangkut pengujian hipotesis. Penelitian semacam ini, dalam deskripsinya juga mengandung uraian-uraian, tetapi fokusnya terletak pada analisis hubungan antara variabel (Hadari,1998).

\section{Teknik Pengumpulan Data}

Data utama yang digunakan adalah data primer. Adapun penggunaan data skunder adalah sebagai pendukung. Data primer dikumpulkan melalui metode persebaran kuesioner kepada responden terpilih di keempat kabupaten di Pulau Madura.

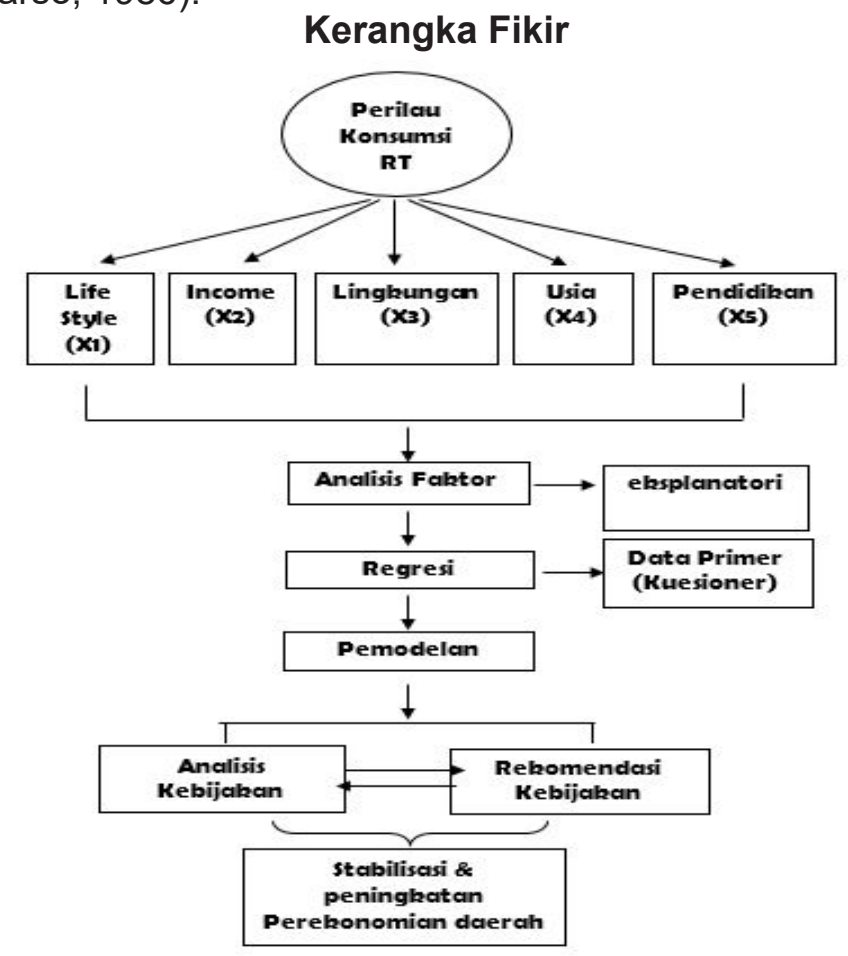


Pengambilan sample minimal menggunakan rumus sebagai berikut:

$$
n \geq p q \quad\left(\frac{z_{1 / 2} \propto}{b}\right)^{2}
$$

dimana: $n=$ jumlah sample minimum; $p=$ proporsi populasi kelompok pertama; $q=$ proporsi sisa di dalam populasi; $z_{1 / 2}=$ derajat koefisien $95 \%$; $b=$ prosentase perkiraan kemungkinan membuat kekeliruan dalam penentuan ukuran sample.

Setelah penentuan jumlah sampel minimum, langkah selanjutnya adalah pengambilan sample melalui teknik purposive sampling.

\section{Hasil dan Pembahasan}

Hasil pengolahan data menunjukkan bahwa variabel lingkungan, pendidikan, pendapatan dan gaya hidup berpengaruh signifikan terhadap tingkat konsumsi pada taraf kesalahan sebesar $10 \%$. Sedangkan variabel usia tidak berpengaruh signifikan terhadap tingkat konsumsi.

Sehingga model tingkat konsumsi di Kabupaten Bangkalan dipengaruhi oleh lingkungan, pendidikan, pendapatan dan gaya hidup.

$\mathrm{Tk}=-3.903193+0.138$ ling $+0.111 \mathrm{pndd}$ +0.729 pndtn -0.363 lifestyle $+\mu$

\section{Faktor Lingkungan}

Berdasarkan uji regresi, observasi lapang dan identifikasi serta hasil analisis kuesioner maka faktor pendorong konsumsi rumah tangga di Bangkalan yang paling besar adalah faktor lingkungan. Secara matematis, setiap perubahan variabel lingkungan sebesar 1 satuan akan berpengaruh terhadap konsumsi rumah tangga sebesar 0,138 satuan. Berdasarkan identifikasi lapang, pola konsumsi rata-rata keluarga di Kabupaten Bangkalan akan mengikuti apa yang sedang banyak dilakukan oleh orang lain. Baik itu dilingkungan tempat mereka bekerja maupun di lingkungan rumah tempat mereka tinggal. Pengaruh tersebut ditunjukkan dengan adanya kecenderungan pembelian barang dan jasa oleh masing-masing rumah tangga. Hal ini terjadi karena informasi banyak mereka dapatkan pada lingkungan tempat bekerja dan lingkungan di sekitar rumah tempat tinggal.

Berdasarkan hasil wawancara, sedikitnya pusat-pusat perbelanjaan menjadi salah satu penyebab mengapa pola konsumsi rumah tangga cenderung untuk mengikuti lingkungan dari pada selera pribadi.

Tabel 1

Hasil Pengolahan Data

Dependent Variable: TINGKAT_KONSUMS Method: Least Squares Sample: 190 Included observations: 90

\begin{tabular}{lrlrc}
\hline \multicolumn{1}{c}{ Variable } & Coefficient & Std. Error & t-Statistic & Prob. \\
\hline LINGKUNGAN & 0.138090 & 0.074286 & 1.858906 & 0.0666 \\
PENDIDIKAN & 0.110569 & 0.063859 & 1.731462 & 0.0871 \\
PENDAPATAN & 0.729043 & 0.258990 & 2.814944 & 0.0061 \\
$\quad$ LIFESTYLE & -0.363332 & 0.159013 & -2.284924 & 0.0249 \\
$\quad$ USIA & 0.007695 & 0.008023 & 0.959057 & 0.3403 \\
C & -3.903193 & 1.561794 & -2.499173 & 0.0144 \\
\hline R-squared & 0.548336 & Mean dependent var & 1.744444 \\
Adjusted R-squared & 0.515686 & S.D. dependent var & 0.930882 \\
S.E. of regression & 0.647826 & Akaike info criterion & 2.044198 \\
Sum squared resid & 34.83333 & Schwarz criterion & 2.238627 \\
Log likelihood & -84.98890 & Hannan-Quinn criter. & 2.122603 \\
F-statistic & 16.79415 & Durbin-Watson stat & 1.931701 \\
Prob(F-statistic) & 0.000000 & & & \\
\hline
\end{tabular}

Sumber: data diolah 


\section{Faktor Pendidikan}

Faktor pendidikan juga berpengaruh signifikan terhadap konsumsi rumah tangga. Setiap peningkatan taraf pendidikan sebasar 1 tingkat akan berpengaruh terhadap pola konsumsi rumah tangga sebesar 0,110 satuan. Berdasarkan hasil observasi lapang, pola konsumsi rumah tangga dengan pendidikan terakhir lebih tinggi akan menyebabkan adanya perbedaan pola konsumsi. Rata-rata rumah tangga dengan pendidikan tinggi di dalam lingkungan keluarganya akan mempunyai pertimbangan yang lebih matang dalam memutuskan untuk berkonsumsi. Sedangkan masyarakat dengan pendidikan yang lebih rendah akan lebih mudah dan lebih cepat dalam memutuska untuk berkonsumsi. Banyak sedikitnya pertimbangan dalam menentukan untuk berkonsumsi dikarenakan adanya ditidaksamaan informasi antara masyarakat yang berpendidikan tinggi dengan masyarakat yang berpendidikan lebih rendah. Oleh karena itu tingkat pendidikan akan mempengaruhi pola konsumsi dari sudut pandang cara menilai pantas atau tidak seseorang untuk memutuskan berkonsumsi.

\section{Faktor Pendapatan}

Faktor pendapatan berpengaruh signifikan terhadap konsumsi rumah tangga sebesar 0,729 . Setiap adanya perubahan pendapatan rumah tangga sebesar 1 satuan akan merubah konsumsi rumah tangga sebesar 0,729 satuan. Pendapatan responden dalam penelitian ini rata-rata ada dalam kisaran antara 2 juta hingga 6 juta rupiah. Hasil wawancara kepada responden tentang apakah akan ada kenaikan konsumsi setiap kali mereka mendapatan tambahan pendapatan. Jawaban masyarakat yang berhasil dihimpun adalah bahwa masyarakat akan memutuskan untuk menambah jenis barang dan jasa yang akan dikonsumsi atau akan menambah kuantitas barang dan jasa yang akan dibeli. Sehingga dapat di- simpulkan bahwa masyarakat Kabupaten Bangkalan akan menambah konsumsinya ketika pendapatan mereka mengalami peningkatan.

Akan tetapi, harapan untuk menambah setiap unit konsumsi tersebut harus dihadapkan dengan jumlah tanggungan dalam keluarga. Jika semakin banyak jumlah tanggungan dan semakin banyak jumlah keluarga maka kebuptusan untuk menambah konsumsi berbasis keinginan atau selera akan dikesampingkan dan beralih pada pemenuhan kebutuhan utama. Hal ini menginsikan tetap akadanya peningkatan jumlah konsumsi dalam rumah tangga tersebut hanya saja yang berbeda adalah peruntukannya.

Hasil survey kepada 91 responden di Kabupaten Bangkalan sebagian besar $54,95 \%$ rumah tangga sudah mempunyai postur pengeluaran yang bagus yakni pengeluaran untuk makanan utama (kebutuhan pokok) lebih sedikit dibandingkan dengan kebutuhan non makanan. Hal ini terkait dengan penjelasan dalam variabel lifesyle dalam point berikut.

\section{Faktor Lifestyle}

Lifestyle berpengaruh signifikan terhadap konsumsi rumah tangga sebesar 0,36 . Stiap perubahan gaya hidup masyarakat akan berpegaruh terhadap konsumsi sebesar 0,36 satuan. Seperti dijelaskan pada point sebelumnya, lifestyle dicerminkan oleh pola pengeluaran dalam rumah tangga. Profil pengeluaran kebutuhan makanan yang lebih besar mengindikasikan bahwa dalam rumah tangga tersebut masih fikus pada kebutuhan pokok yang artinya kesejahteraannya lebih rendah dibandingkan dengan rumah tangga yang memiliki pola pengeluaran non makanan lebih besar.

\section{Penutup}

Kesimpulan yang bisa diperoleh dari hasil kajian penetilian ini antara lain: (a) Rumah tangga di Kabupaten 
Bangkalan menentukan konsumsi mereka berdasarka 4 (empat) faktor yaitu: pengaruh lingkungan, pengaruh pendidikan, pendapatan, serta pengaruh gaya hidup; (b) Usia tidak berpengaruh pada keputusan untuk berkonsumsi dikarenakan pada tingkat usia yang dianalisis ditemukan kesamaan kecenderungan untuk menentukan pilihan konsumsi; (c) Ditinjau dari sudut pandang kesejahteraan, hasil analisis pola konsumsi rumah tangga di Kabupaten Bangkalan menunjukkan bahwa rumah tangga di Kabupaten Bangkalan termasuk pada kriteria sejahtera dengan mengacu pada peruntukan pengeluaran. Peruntukan pengeluaran menunjukkan bahwa rata-rata rumah tangga di Kabupaten Bangkalan pengeluaran non makanan lebih besar dari pengeluaran makanan.

\section{Daftar Pustaka}

1985. "Excess Sensitivity of Consumption to Current Income: Liquidity Constraints or Myopia?", The Canadian Journal of Economics, 18(1). 2003. Makroeconomics 5th Edition. New York and Basingstoke by Worth Publishers.

Browning, Martin dan Thomas F Crossley. 2001. "The Life-Cycle Model of Consumption and Saving". The Journal of Economic Perspectives, 15(3). Published by American Economic Association.

Dornbusch, Rudiger dan Stanley Fisher. 1987. Macroeconomics. Sixth edition.m McGraw - Hill, Inc, New York.

Eilenstine, Donald dan James P Cunningham. 1972. Projected Consumption Patterns for a Stationary Population. JSTOR, Population Studies, 26(2).

Flavin, Marjorie. 1981. "The Adjustment of Consumption to Changing Expectations about Future Income". Journal of
Political Economy, 89(51). University of Chicago.

Hall, Robert. E dan Frederic S Mishkin. 1982. "The Sensitivity of Consumpton to Transitory Income: Estimates From Panel Data on Households". Journal Econometrica, 50(2).

Jaeger, Albert. 1992. "Does Consumption Take a Random Walk? Some Evidence from Macroeconomic Forecasting Data", The Review of Economics and Statistics, 74(4). Published by The MIT Press.

Konya, Istvan dan Ohashi Hiroshi. 2005. International Consumption Patterns Among High-Income Countries: Evidence From OECD Data. CIRJE Discussion Papers, March. University of Tokyo, Japan.

Mannan, MA, 1997. Teori dan Praktek Ekonomi Islam, Edisi Terjemahan. Dana Bhakti Wakaf, Seri Ekonomi Islam No. 02. Edisi Lisensi, Yogyakarta.

Mankiw, Gregory N. 1997. Makroeconomics 4th Edition. New York and Basingstoke by Worth Publishers.

Nicholson, walter. 1997. Intermediet Micro economics and its aplication 7th Edition. The dryden press.

Ratnawati, Nirdukita dan Rizki, Rulli. 2004. "Analisis Pengaruh Variabel Indikator Makro Ekonomi Terhadap Ekonomi Makro Indonesia, Pendekatan Pasar Barang dan Pasar Uang, Periode 1990.1 - 2003.4. Jurnal Media Ekonomi, 10(3). LPFE, Universitas Trisakti Jakarta. 